Tropical Journal of Pharmaceutical Research, June 2002; 1 (1): 3-14

(C) Pharmacotherapy Group, Faculty of Pharmacy, University of Benin, Benin City, Nigeria. All rights reserved.

Available online at http://www.tjpr.freehosting.net

Review Article

\title{
Experimental and modeling studies of mass transfer in microencapsulated cell systems
}

\section{Mattheus F. A. Goosen}

Department of Bioresource and Agricultural Engineering, College of Agriculture and Marine Sciences, Sultan Qaboos University, P.O. Box 34, Al-Khod 123, Sultanate of Oman. Fax: +968 515418 Fax: +968 515200

E-mail: theog@squ.edu.om (Business); mattheus@omantel.net.om (Home)

\section{Abstract}

Gaining a better understanding of mass transfer problems in encapsulated cell systems and in tissue engineering requires both experimental investigations and mathematical modelling. Specific mass transfer studies are reviewed including oxygen transfer in immobilised animal cell culture systems, modelling of electrostatic polymer droplet formation, and growth of plant somatic tissue encapsulated in alginate using electrostatics. 


\section{Introduction}

Microencapsulation systems have found applications in encapsulated cell therapy/tissue engineering ${ }^{1-3}$, bioseparations technology ${ }^{4}$, immobilized biocatalysts ${ }^{5,6}$, and polymeric drug-delivery systems ${ }^{7,8}$. All areas, however, suffer from specific mass transfer problems. With drug-delivery systems, the release of the bioactive agent from the polymer matrix or capsule must be controlled so as to provide a constant steady release rate. In the case of immobilized cells, oxygen must be able to reach the viable cells at a sufficient rate to keep the cells alive, while the desired product, such as insulin in the case of diabetes treatment, must diffuse out of the capsule, along with low molecular weight waste products. With biocatalysts, whether they be enzymes or cells, the substrate must be able to reach the bead/capsule interior to allow the biochemical reaction to occur and the desired products must be able to diffuse out of the bead.

This objective of this paper was to review specific mass transfer studies performed in our laboratory including oxygen transfer in immobilized animal cell culture bioreactors, modelling of electrostatic polymer droplet formation, and growth of somatic tissue encapsulated in alginate using electrostatics. Both experimental and modelling studies were combined so as to give the reader a better insight into common mass transfer problems.

\section{Modelling of the oxygen transfer process in immobilized cell systems}

It is not adequate simply to transfer sufficient oxygen to the bulk liquid culture medium in immobilized cell systems. Oxygen must also be transferred from the liquid to the cells. Consider for instance the transfer of oxygen from a gas bubble, through the culture medium to a microcapsule containing animal cells. The resistance to oxygen transfer from the gas phase to the inside edge of the microcapsule (i.e. gas to liquid, liquid to microcapsule, and trans-membrane resistance) (Figure 1) can be added together resulting in the following expression for the resistance to oxygen transfer, $R^{9,10,11}$ :

$\mathrm{R}=\frac{1}{\mathrm{~V}_{\mathrm{L}} \mathrm{k}_{1} \mathrm{a}}+\frac{1}{\mathrm{~V}_{1} \mathrm{k}_{\mathrm{s}} \mathrm{a}}+\left[\frac{\frac{1}{\mathrm{r}_{0}}-\frac{1}{\mathrm{r}_{\mathrm{i}}}}{4 \pi \mathrm{nD}_{\mathrm{O}_{2}, \mathrm{~m}}}\right]$

where $V_{L}$ is the volume of the liquid phase, $n$ is the number of microcapsules, $r_{o}$ and $r_{i}$ are the outside and inside radius of the microcapsule, respectively, $\mathrm{k}_{\mathrm{s}} \mathrm{a}$ is the volumetric mass transfer coefficient from a liquid to a solid, and $D_{O 2, m}$ is the diffusivity of oxygen in the membrane.

Employing Fick's Law of Diffusion ${ }^{12}$, it can be shown that the oxygen transfer rate from the gas phase to the inside edge of a microcapsule, $\mathrm{OTR}_{\mathrm{G}}$, is given by:

$\operatorname{OTR}_{G}=\left[\frac{1}{V_{L} k_{l} a}+\frac{1}{V_{L} k_{s} a}+\frac{\frac{1}{r_{o}}-\frac{1}{r_{i}}}{4 \pi n D_{o_{2}, m}}\right]^{-1}\left(C^{*}-C_{i, m, i}\right) \geq Q=Q_{o_{2}} x$

where $C^{*}$ is the oxygen concentration in equilibrium with the oxygen partial pressure in the gas phase, $C_{i, m, i}$ is the oxygen concentration on the inside of the membrane, $Q$ is the oxygen consumption rate of cells inside a microcapsule $\left(\mathrm{mgO}_{2} / \mathrm{Lhr}\right), Q_{\mathrm{O} 2}$ is the oxygen consumption rate per cell, and $x$ is the cell density. To enable the cells in the microcapsule to survive, the oxygen transfer rate, OTR $R_{G}$, must be greater than (or at least equal to) the oxygen consumption rate of cells inside the capsules, $Q$. Based on the work of Heath and Belfort ${ }^{13}$ the oxygen concentration profile within a microcapsule can be represented by:

$C_{i, m, i}-C_{o}=\frac{Q}{D_{o_{2}, a}} \frac{1}{6} r^{2}$ 


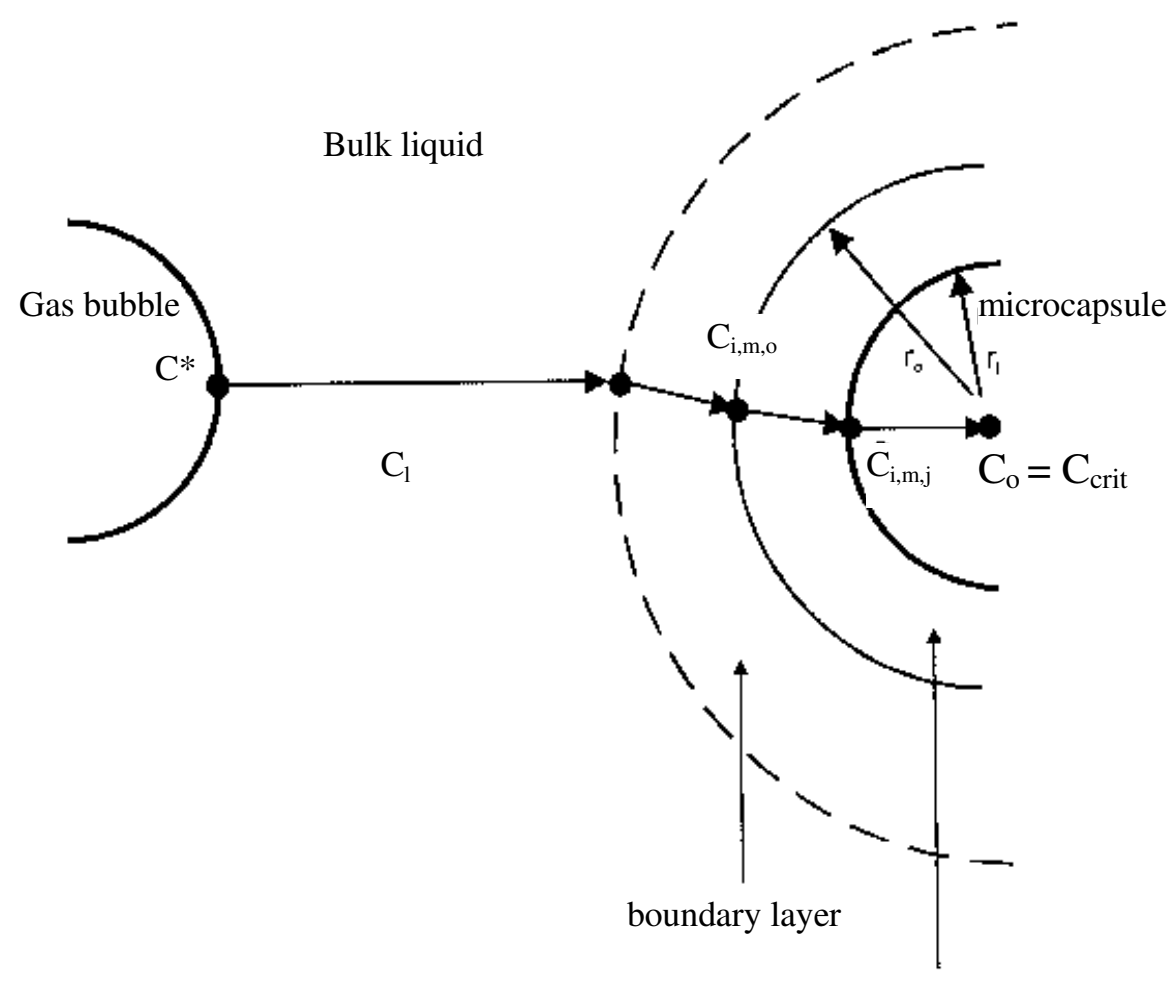

membrane

Figure 1: Schematic Diagram of Oxygen Profile from Gas Bubble to Center of Microcapsule ${ }^{10}$

where $r$ is the radius of the alginate core. If the concentration of oxygen in the center of the microcapsules, $C_{o}$, is equal to a critical oxygen concentration, $C_{\text {crit, }}$, the concentration of oxygen at the inner surface of the membrane, $C_{i, m, i}$ can be determined from equation 3.

The performance of a one liter external-loop air-lift bioreactor was investigated by studying the gas-liquid oxygen transfer at various aeration rates $(0.1 \mathrm{vvm}$ to $1.06 \mathrm{vvm})$. The influence of suspended alginate beads on the hydrodynamics and mass transfer of the system was examined over a range of microbead loadings ( 0 to $25 \%$ by volume). The intent was to investigate the effect of using various concentrations of cell immobilization matrices on the physical properties of the system. A mathematical correlation was developed for expressing the dependence of $\mathrm{k}_{1} \mathrm{a}$ on aeration rate and microbead loading. A mathematical study of the mass transfer resistances from the gas phase to the interior of a microcapsule was also performed, using experimentally determined $\mathrm{k}_{\mathrm{l}} \mathrm{a}$ values, to enable the determination of the maximum bioreactor microcapsule loading.

The oxygen probe time constant for our studies was $27 \pm 7 \mathrm{sec}$ and the maximum $k_{r} a$ value found was $0.00861 \mathrm{sec}^{-1}$. Since this is approximately equal to $1 / 5 k_{l} a$, the oxygen probe response time was therefore not accounted for in the determination of the $k_{l} a$ values in our investigation. According to Van't Riet ${ }^{14}$, the response lag of an oxygen 


\section{MFA Goosen}

probe can be neglected if the oxygen probe time constant, $\tau_{\mathrm{p}}$, is less than $1 / 5 k_{r} a$.

To ensure that the $k, a$ studies would be measuring the gas-to-liquid mass transfer coefficient and not the mass transfer from the gas to the interior of the bead, the $k_{l} a$ in the presence of alginate beads was compared to that in the presence of ion-exchange resin beads. The $k_{l} a$ for a $10 \%$ loading of alginate beads it was determined to be $31.7 \pm 0.7 \mathrm{hr}^{-1}$ and for a $10 \%$ loading of ion-exchange resin beads it was $31.4 \pm 1.5 \mathrm{hr}^{-1}$, at an aeration rate of $0.67 \mathrm{vvm}$. The $k_{l} a$ values are essentially equal. This suggested that the alginate beads were not acting as a "sink" for oxygen and that the desired quantity, gas-toliquid mass transfer coefficient, was being measured.

For immobilized cell systems, such as microcapsules, ensuring adequate oxygen transfer from the gas phase to the liquid medium does not necessarily ensure that adequate oxygen will reach the immobilized cells. It is possible that the $\mathrm{k}_{1} \mathrm{a}$ may not be adequate for a certain microcapsule loading. A theoretical study was performed in our laboratory of oxygen transfer to cells immobilized in microcapsules in a bioreactor for various microcapsule loadings using equations 2 and $3^{10}$. A schematic diagram of the oxygen concentration profile from a gas bubble to the center of a microencapsule is shown in Figure 1. Upon arbitrarily specifying the critical oxygen concentration in the center of the microcapsule, the rate of oxygen transfer from the gas phase to the inner surface of the microencapsule membrane $\left(O T R_{G}, \mathrm{mg} / \mathrm{hr}\right)$ for a certain microcapsule loading was compared to the oxygen demand of the cells $\left(Q_{O 2}, X\right)$ for the same microcapsule loading. The study was made for Spodoptera frugiperda (i.e. insect) cells cultivated in poly1-lysine/alginate microcapsules at a maximum cell density of $8 \times 10^{7}$ cells $/ \mathrm{mL}$ capsules ${ }^{15}$. An oxygen demand of $1.4 \times 10^{-10} \mathrm{mmole}_{2} / \mathrm{cell} \mathrm{hr}$ was assumed. These insect cells are usually cultivated at $27^{\circ} \mathrm{C}$ and $33^{\circ} \mathrm{C}$ therefore our study was performed at both temperatures. It was necessary to estimate several of the parameters used to evaluate the oxygen transfer rate. The diffusivity of oxygen in sodium alginate (the immobilization agent inside the microcapsule) was estimated to be $86 \%$ of the diffusivity of oxygen in water (i.e. approximately the same as the diffusivity of oxygen in calcium alginate). According to King et al. ${ }^{15}$, the membrane is 5 im thick and is composed of approximately $90 \%$ water. The diffusivity of oxygen through the membrane was therefore assumed to be equal to that of oxygen in water. A critical oxygen concentration in the center of the microcapsule was assumed to be $40 \%$ of air saturation.

Figure 2 shows the results for the oxygen transfer rate, OTR attainable for microcapsule loadings of 10,15 and $25 \%$ at $33{ }^{\circ} \mathrm{C}$ and 27 ${ }^{\circ} \mathrm{C}$ as a function of the aeration rate. The terminal settling velocity was used to calculate the Reynold's number. Comparing Figures $2 \mathrm{~A}$ and $2 \mathrm{~B}$, the latter uses the difference between the bead and liquid velocities (determined experimentally) to calculate the Reynold's number, and indicates that there is not much difference (at most $8 \%$ ) between the two methods. This suggests that the terminal velocity may be used as a good approximation of the relative velocity between the bead and the liquid if it is not feasible to determine the liquid and bead velocities experimentally.

At $33{ }^{\circ} \mathrm{C}$, for $10 \%$ bead loading, the oxygen demand of the cells was achieved at 0.29 vvm, which is the minimum vvm for suspension of the beads (Figure 2A). On the other hand, for $25 \%$ bead loadings a vvm of 1.06 is required to meet the oxygen demand of the cells. This is quite a high aeration rate thus it may not be feasible to operate at $25 \%$ bead loading. Decreasing the temperature to $27^{\circ} \mathrm{C}$ (Figures 2C and 2D) increased the oxygen transfer rate but only slightly (by approximately $8 \%$ ). This was expected since a decrease in temperature increases the solubility of oxygen in the bulk liquid which 


\section{MFA Goosen}
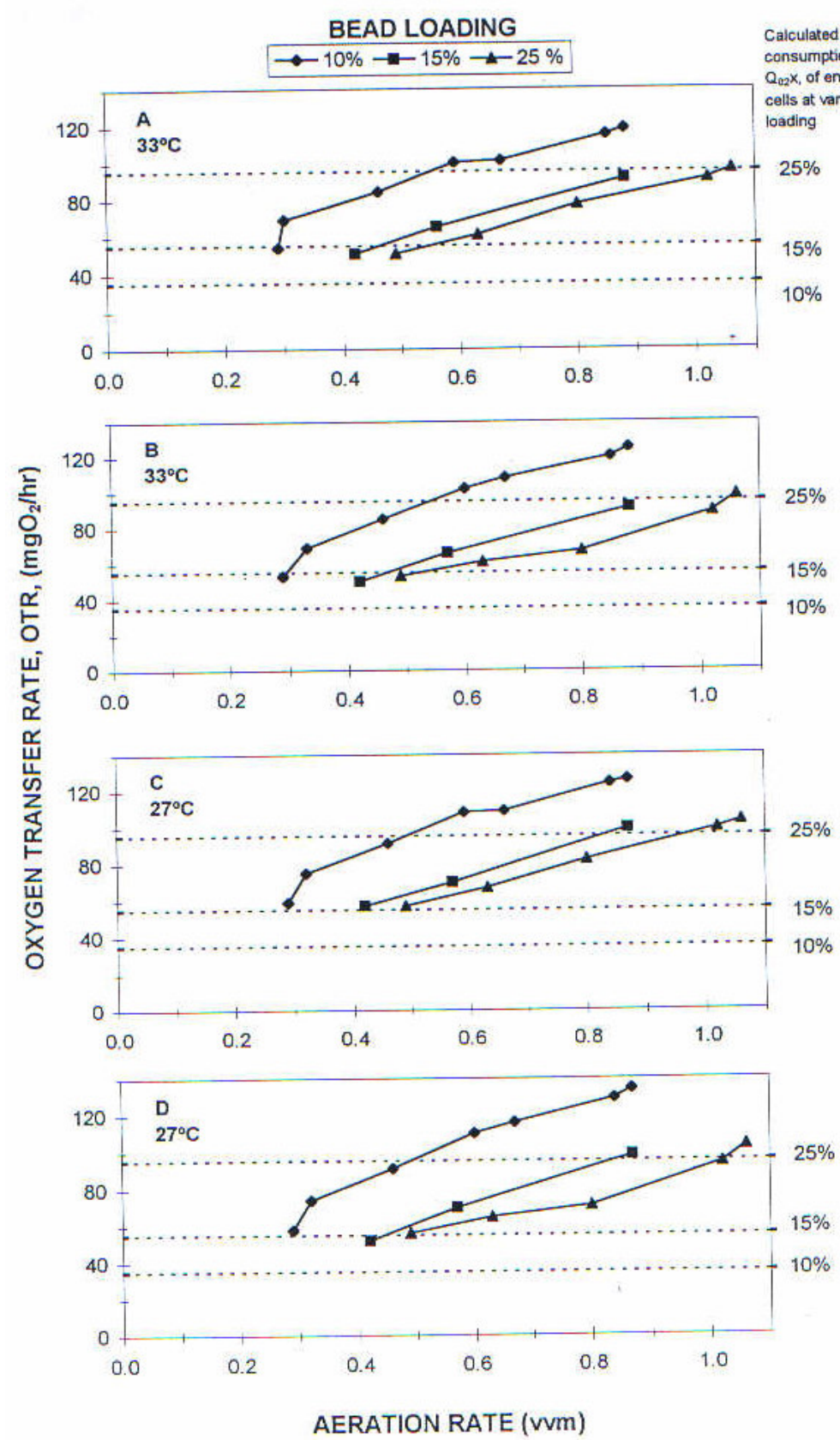

Figure 2: Theoretical Oxygen Transfer Rate ,OTR, as a Function of Aeration Rate for Encapsulated Insect Cells in Bioreactor at $33 \mathrm{C}$ Using the Terminal Settling Velocity to Calculate the Reynold's Number (A); OTR at $33 \mathrm{C}$ Using the Difference Between the Bead Velocity and the Liquid Velocity to Calculate the Reynold's Number (B); OTR at 27 C Using the Terminal Settling Velocity to Calculate the Reynold's Number (C); OTR at 27 C Using the Difference Between the Bead Velocity and the Liquid Velocity to Calculate the Reynold's Number (D) ${ }^{10}$ 


\section{MFA Goosen}

increases the driving force for oxygen transfer. This, in turn, increases the oxygen transfer rate to the cells. The temperature did not, however, have a very significant effect on the oxygen transfer rate. These results suggest that for this bioreactor the cells will not be oxygen limited at microcapsule loadings of $10 \%$ and $15 \%$ (by volume). However, there is the potential for oxygen limitation at $25 \%$ microcapsule loadings if the reactor is not operated at a minimum aeration rate of 1.06 vvm.

\section{Mathematical modeling of electrostatic polymer droplet formation}

Droplet formation in the presence of an electric field has been analyzed previously ${ }^{6}$. If gravity were the only force acting on the meniscus of a droplet attached to the end of a tube, large uniformly sized droplets would be produced. The gravitational force, $F_{g}$, pulling the droplet from the end of the tube is given by:

$$
\mathrm{F}_{\mathrm{g}}=\frac{4}{3} \pi \mathrm{r}^{3} \rho \mathrm{g}
$$

where $\rho$ is the density of the polymer solution, $r$ is the droplet radius and $g$ is the acceleration due to gravity. The capillary surface force, $F_{\gamma}$, holding the droplet to the end of the tube is given by:

$$
\mathrm{F}_{\gamma}=2 \pi \mathrm{r}_{0} \gamma
$$

where $r_{0}$ is the internal radius of the tube and $\gamma$ is the surface tension.

Equating the gravitational force on the droplet to the capillary surface tension force holding the droplet to the tube (i.e. extrusion orifice) gives:

$r=\left[\frac{3 r_{0} \gamma}{2 \rho g}\right]^{1 / 3}$

In the presence of an applied voltage, the electric force, $F_{e}$, acting along with the gravitational force, $F_{g}$, would reduce the critical volume for drop detachment resulting in a smaller droplet diameter. Equating the gravitational and electrical forces on the droplet to the capillary surface force, $F_{\gamma}$, yields:

$\mathrm{F}_{\gamma}=\mathrm{F}_{\mathrm{g}}+\mathrm{F}_{\mathrm{e}}$

In the case of a charged needle, the stress produced by the external electric field at the needle tip is obtained by using a modified expression developed by De Shon and Carlson 17:

$$
\mathrm{F}_{\mathrm{e}}=4 \pi \varepsilon_{\mathrm{o}}\left[\frac{\mathrm{V}}{\operatorname{Ln}\left(\frac{4 \mathrm{H}}{\mathrm{r}_{0}}\right)}\right]^{2}
$$

where $H$ is the distance between the needle tip and collecting solution, $V$ is the applied voltage, and $\varepsilon_{0}$ is the permittivity of the air.

The effect of applied potential on the droplet radius for a charged needle arrangement can be derived by substituting equations 4,5 and 8 into equation 7:

$$
r=\left(\left[\frac{3}{2 \rho g}\right]\left[r_{0} \gamma-2 \varepsilon_{0}\left(\frac{V}{\operatorname{Ln}\left(\frac{4 H}{r_{0}}\right)}\right)^{2}\right]\right)^{1 / 3}
$$

Equation 6 was employed to calculate the microbead diameter in the absence of an applied voltage (i.e., $0 \mathrm{kV}$ ). The surface tension, $\gamma$, of the alginate solution was assumed to be $73 \mathrm{~g} / \mathrm{s}^{2}$ which i $\varepsilon_{0}$ s the value for water against air ${ }^{18}$. The density of the polymer solution was taken as $1 \mathrm{~g} / \mathrm{cm}^{3}$. In the presence of an applied voltage, equation 9 was used to determine microbead size. The permittivity of air, , used in calculations was 


\section{MFA Goosen}

$1.0 \mathrm{~g} \mathrm{~cm} / \mathrm{s}^{2} \mathrm{kV}^{2}$. This value was estimated based on previous studies ${ }^{16}$.

Reasonably good agreement was obtained between calculated and experimental values of microbead diameter (Table 1) ${ }^{19}$. For example, when the extrusion orifice diameter decreased from 1900 to 400 microns, the calculated bead diameters decreased from 4400 to 2600 microns, and the experimental values decreased from 3700 to 2000 microns. When the extrusion orifice diameter was kept constant at 1900 microns and the applied voltage was increased from 0 to $10 \mathrm{kV}$, there was also a similar decrease in bead size from 4400 to 1690 microns for the calculated values and from 3700 to 1700 microns for the experimental values.

Table 1: Comparison of experimental and calculated microbead diameter as a function of extrusion orofice size and applied potential

\begin{tabular}{cccc}
\hline \multirow{2}{*}{$\begin{array}{c}\text { Extrusion } \\
\text { diameter } \\
\text { (microns) }\end{array}$} & $\begin{array}{c}\text { Applied } \\
\text { potential, } \\
(\mathrm{kV})\end{array}$ & $\begin{array}{c}\text { Microbead diameter } \\
\text { (microns) }\end{array}$ \\
\cline { 3 - 4 } & & Calculated $^{\dagger}$ & Experimental $^{\ddagger}$ \\
\hline & & & \\
400 & 0 & 2600 & 2000 \\
1000 & 0 & 3500 & 2800 \\
1900 & 0 & 4400 & 3700 \\
1900 & 5 & 4018 & 3500 \\
1900 & 10 & 1680 & 1700 \\
\hline
\end{tabular}

${ }^{+}$Bead size at $0 \mathrm{kV}$ was determined using equation 3 and 5 and 10 $k V$ using equation 6 .

${ }^{\ddagger}$ Bead size using $4 \% \mathrm{w} / \mathrm{v}$ non-autoclaved sodium alginate in water with an electrode distance of $6 \mathrm{~cm}$ and a $22 \mathrm{G}$ needle $\left(r_{0}=500\right.$ microns)

\section{Encapsulation and growth of somatic tissue in alginate using electrostatics}

The mechanism of alginate droplet information using an electrostatic droplet generator has recently been investigated with a variable-voltage power supply ${ }^{20-23}$. Animal cell suspensions were successfully extruded using the electrostatic droplet generator. The application of this technology to plant cell immobilization has only recently been reported ${ }^{11,19,23}$. A major concern in cell and bioactive agent immobilization has been the production of very small microbeads so as to minimize the mass-transfer resistance problem associated with large-diameter beads $(>1000 \mu \mathrm{m})$. Klein et al. ${ }^{24}$ reported production of alginate beads with diameters from 100 to $400 \mu \mathrm{m}$ using compressed air to quickly pass the cell/gel solution through a nozzle. Few attempts have been made in the application of electric fields to the production of micron size polymer beads for cell immobilization ${ }^{25}$.

Somatic embryogenesis is a new plant tissue culture technology in which somatic cells (i.e., any cell except a germ or seed cell) are used to produce an embryo (i.e., plant in early state of development) ${ }^{26}$. The technique of somatic embryogenesis in liquid culture, which is believed to be an economical way for future production of artificial seeds, may benefit from cell immobilization technology. Encapsulation may aid in the germination of somatic embryos by allowing for higher cell densities, protecting cells from shear damage in suspension culture, allowing for surface attachment in the case of anchorage dependent cells, and being very suitable for scale-up in bioreactors.

The long-term objective of the project reported in this section is the development of an economical method for the mass production of artificial seeds using somatic embryogenesis and cell immobilization technology. The short-term aim was to investigate the production of small alginate microbeads using an electrostatic droplet generator. Callus tissue from Carnation leaves was also immobilized and cultured. The section starts with a detailed experimental description of electrostatic 
droplet generation for those not familiar with the technique ${ }^{22}$ (Figure 3 ).

\section{Production of Alginate Beads using Electrostatics}

Attach a syringe pump to a vertical stand. Use a $10 \mathrm{~mL}$ plastic syringe and 22- or 26gage stainless steel needles. A variable high voltage power supply $(0-30 \mathrm{kV})$ with low current (less than $0.4 \mathrm{~mA}$ ) is required. We have used a commercial power supply model 230-30R from Bertan (Hicksville, NY).

Prepare $1.5 \%(\mathrm{w} / \mathrm{v}) \mathrm{CaCl}_{2}$ in saline $(0.85$ $\mathrm{g} \mathrm{NaCl}$ in $100 \mathrm{~mL}$ distilled water). Saline can be replaced with distilled water if an alginate solution without cells is being extruded. Place the $\mathrm{CaCl}_{2}$ solution in a petri dish on top of an adjustable stand. The stand allows for fine tuning of the distance between the needle tip and collecting solution. Prepare 1 to $4 \%(\mathrm{w} / \mathrm{v})$ low viscosity sodium alginate by dissolving alginate powder with stirring in a warm water bath. Slowly add the 1 to $4 \mathrm{~g}$ sodium alginate to $100 \mathrm{~mL}$ warm saline solution (or distilled water), stirring continuously. It may take several hours to dissolve all of the alginate. Add about $8 \mathrm{~mL}$ of the alginate solution to a $10-\mathrm{mL}$ plastic syringe, put back the plunger, and attach the syringe to the upright syringe pump. Make sure that the stainless steel needle, 22 gage, is firmly attached and the syringe plunger is in firm contact with the moveable bar on the pump. Position the petri dish (or beaker) containing $\mathrm{CaCl}_{2}$ so that the needle tip is about $3 \mathrm{~cm}$ from the top of the $\mathrm{CaCl}_{2}$ hardening solution. This is the primary reason for using an adjustable stand.

Attach the positive electrode wire to the stainless steel needle and the ground wire to the collecting solution. The wires may need some additional support to prevent them from bending the needle. Switch on

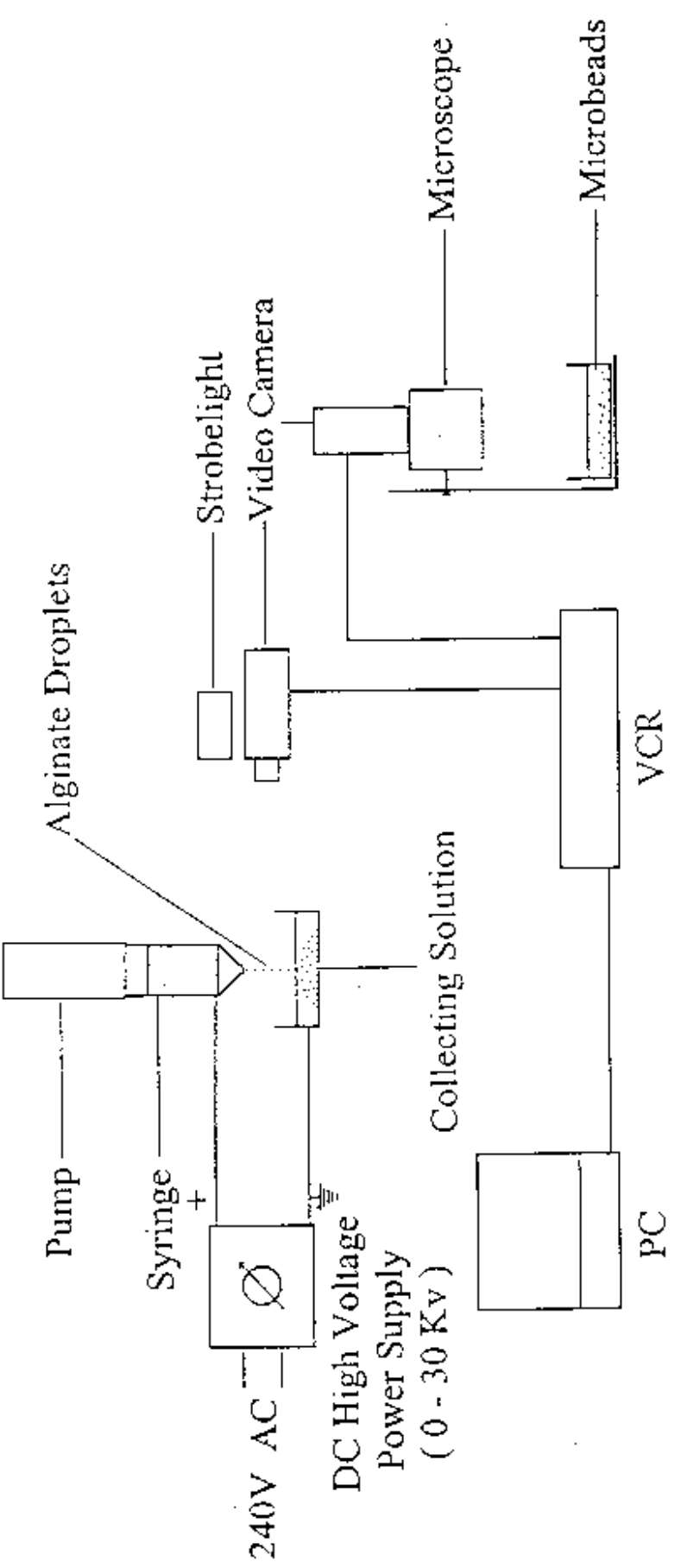

Figure 3: Electrostatic droplet generation system ${ }^{19}$ 


\section{MFA Goosen}

the syringe pump and wait for the first few drops to come out of the end of the needle. This could take a minute or two. Doing it this way also ensures that the needle that the needle is not plugged. After the first drop or two has been produced, switch on the voltage supply. Make sure that the voltage is set low, less than $5 \mathrm{kV}$. If this is the first time that you have tried electrostatic droplet generation, raise the voltage slowly and observe what happens to the droplets. The rate at which they are removed from the needle tip increases until only a fine stream of droplets can be seen. The changeover from individual droplets to a fine stream can be quite dramatic. The most effective electrode and charge arrangement for producing small droplets is a positively charged needle and a grounded plate. Two other arrangements are also possible; positively charged plate attached to needle, and a positively charged collecting solution. Make sure that the positive charge is always on the needle. This ensures that the smallest microbead size is produced at the lowest applied potential. With a 22-gage needle and an electrode spacing of $2.5-4.8 \mathrm{~cm}$ there will be a sharp drop in microbead size at about $6 \mathrm{kV}$. This can be noticed visually by observing the droplets coming from the needle tip. Standard commercially available stainless steel needles can be employed. However, when going from a 22- to 26-gage (or higher) needle, needle oscillation may be observed. This needle vibration will produce a bimodal bead size distribution with one peak around $50 \mathrm{~mm}$ diameter beads and another around $200 \mathrm{~mm}$.

If a syringe pump is not available, remove the syringe plunger and attach an air line with a regulator to the end of the syringe. Varying the air pressure on the regulator can control the alginate extrusion rate.

Lumps of sodium alginate often form if the powder is added all at once to the warm saline. Sprinkle the alginate powder into the saline a small amount at a time with gentle mixing. Once it has dissolved (up to 1-2 h), allow the viscous solution to cool and then transfer it to several plastic test tubes, cap and store in the refrigerator until needed. This prevents bacterial growth. If the alginate solution is very viscous, air bubbles will be trapped during the stirring. These bubbles will disappear if the viscous solution is left to stand overnight.

If the needle is plugged, place it in dilute citrate solution for a few minutes. Passing a fine wire through the needle also helps. Resuspending cells in $1 \%(\mathrm{w} / \mathrm{v})$ sodium alginate solution will dilute the alginate and could give tear-drop shaped beads when the solution is extruded. To solve this problem, increase the concentration of sodium alginate solution to 3 or $4 \%$.

Extrusion of alginate droplets using a $5.7 \mathrm{KV}$ fixed-voltage power supply showed that there is a direct relationship between the electrode distance and the bead diameter. For example, at $10-\mathrm{cm}$ electrode distance, the bead diameter was $1500 \mu \mathrm{m}$ while at $2 \mathrm{~cm}$ it decreased to $800 \mu \mathrm{m}$. The greatest effect on bead diameter was observed between 2 and $6 \mathrm{~cm}$ electrode distance. While there was overlap in bead sizes between 6,8 and $10 \mathrm{~cm}$ electrode distance, there was a significant difference (i.e., no overlap in SD) between bead sizes at 2 and 6 -cm electrode distance. An inverse relationship between needle size and microbead diameter was observed. Aside from the $23 \mathrm{G}$ needle there was a significant difference between bead sizes produced by all needles (i.e., no SD overlap). As the needle size decreased from 19 to 26 $\mathrm{G}$, the bead size decreased from 1400 to 400 $\mu \mathrm{m}$, respectively. These results support previous work reported by Bugarski et al. ${ }^{21}$. The present investigation showed that the alginate concentration does not appear to be important due to overlapping SD intervals for all data points. The bead diameter was found to be $800 \mu \mathrm{m}$ at both $1 \%$ and $3 \%$ alginate concentration. 
Looking more closely at the effect of needle size on bead diameter, as a function of applied potential (Figure 4) we see that the decrease in microbead size was greatest between 5 and $10 \mathrm{KV}$ for all needle gages tested. For example, when the applied potential was increased

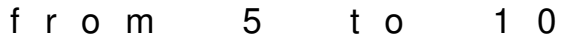
$\mathrm{KV}$, the microbead diameter decreased from 2000 to $1000 \mu \mathrm{m}$ and from 1000 to $250 \mu \mathrm{m}$ for the 19 and $26 \mathrm{G}$ needles, respectively. The smallest bead, $200 \mu \mathrm{m}$, was produced with a $26 \mathrm{G}$ needle at 20 $\mathrm{KV}$.

\section{Immobilised Callus Tissue Growth}

Immobilized callus cells from carnation leaves retained viability as observed by cell growth and plantelet formation 11, 19, 23. In a related study, Shigeta ${ }^{27}$ was able to germinate and grow encapsulated somatic embryos of carrot using a $1 \%$ sodium alginate solution, as compared to a $2 \%$ alginate solution used in the present investigation. The main findings of our experiment, though, indicated that somatic tissue could be electrostatically extruded and aseptically cultured while retaining viability.

Plantlets obtained from $4 \%$ alginate beads on agar, originally immobilized at $10 \mathrm{kV}, 6 \mathrm{~cm}$ distance, were transferred to sterilized potting mixture at two months culture. The plantlets grew well and showed complete leaf and root development by four months ${ }^{19}$. Suspension culture of encapsulated somatic tissue was less successful. Piccioni ${ }^{28}$ in a recent study investigated the growth of plantlets from alginate encapsulated micropropagated buds of M.26 apple rootstocks. He showed that the addition of growth regulators (e.g.,
NEEDLE SIZE (GUAGE)

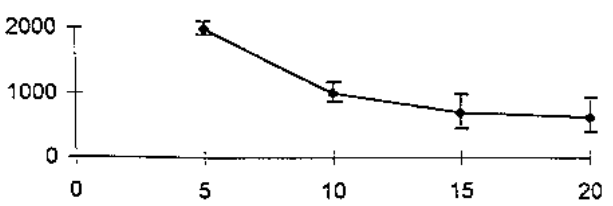

19

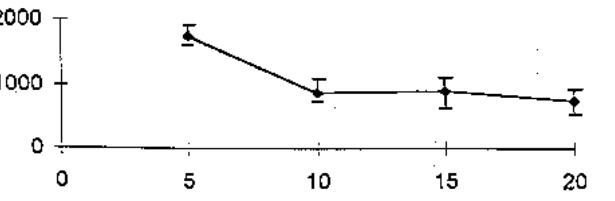

21

23

25

26

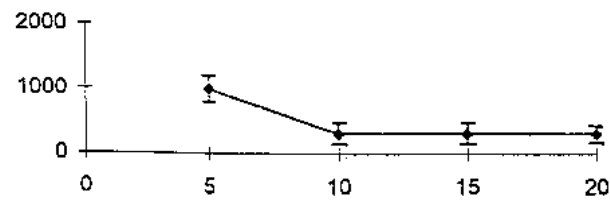

APPLIED POTENTIAL $(\mathrm{kV})$

Figure 4: Effect of needle size and applied potential on microbeed diameter $( \pm s d)^{10}$

indolebutyric acid) to the somatic tissue culture several days prior to the encapsulated, as well as the addition of the same regulators to the encapsulation matrix, improved the production of plantlets in suspension culture from $10 \%$ to more than $60 \%$. We can speculate that culturing the Carnation leaf callus tissue in the presence of growth 
regulators prior and during encapsulation may enhance the production of plantlets from suspension culture.

Electrostatic droplet generation does not appear to have a negative impact on somatic tissue viability since cell growth and plantlet formation was observed. This is in agreement with similar studies reported for insect cells ${ }^{29}$ and mammalian cells ${ }^{25}$, where it was shown that high electrostatic potentials did not affect cell viability. In closing, the technique also has great potential in medicine for encapsulating genetically engineered cells ${ }^{30}$ and in environmental engineering for removal of heavy metals from water using gel beads ${ }^{31}$.

\section{Concluding remarks}

In the coming decade, the development of commercially-successful microencapsulated cell systems will necessitate close collaboration between scientists with different areas of expertise such as engineering, microbiology, biochemistry, pharmacology and medicine. As our knowledge of the physicochemical and mass transfer characteristics of such systems increases, we can expect to see many new areas of application. This is an opportunity that should not be missed.

\section{Acknowledgments}

The financial support of the Natural Science and Engineering Research Council of Canada, and Sultan Qaboos University, College of Agriculture (Grant AGBIOR 9505 to Mattheus Goosen) is gratefully acknowledged.

\section{References}

1. Langer R. Biomaterials: Status, challenges, and perspectives. AIChE J., 2000, 46: 1286-1289.

2. Lanza RP, Hayes JL, Chick WL. Encapsulated cell technology. Nature Biotechnology, 1996, 14: 1107-1111.

3. Stegemann, JP, Sefton MV. Video Analysis of Submerged Jet Microencapsulation Using HEMA-MMA. CJChE, 1996, 74: 518-525.

4. Li Q, Goosen MFA, Grandmaison EW, Taylor D. Convection-enhanced mass transfer in aggregated beads for gel chromatography. AIChE J. (accepted 20 March 2000).

5. Svec F, Gemeiner P. Engineering aspects of carriers for immobilized biocatalysts. Biotechology and Genetic Engineering Reviews, 1995, 13: 217-235.

6. Takizawa S, Aravinthan V, Fujita K. Nitrogen removal from domestic wastewater using immobilized bacteria. Wat. Sci. Tech., 1996, 34 (1-2): 431-440.

7. Yao K, Peng T, Xu M, Yuan C. pH-Dependent hydrolysis and drug release of chitosan/polyether interpenetrating polymer network hydrogel. Polymer Int'l, 1994, 34:213219.

8. Gan KHW, Geus PW, Bakker CBHW, Lamer. Heijerman HGM. In vitro dissolution profiles of enteric-coated microsphere/microtablet pancreatin preparations at different $\mathrm{pH}$ values. Aliment Pharmacol Ther., 1996, 10: 771-775.

9. Linek V, Vacek V, Benes $P, A$ critical review and experimental verification of the correct use of the dynamic method for the determination of oxygen transfer in aerated agitated vessels to water, electrolyte solutions and viscous liquids, Chemical Engineering Journals, 1987, 34: 1134.

10. Sharp NA, Daugulis AJ, Goosen MFA Hydrodynamic and mass transfer studies in an external-loop air-lift bioreactor for immobilized animal ell culture. Applied Biochemistry and Biotechnology, 1998, 73 (1): 57-77.

11. Goosen MFA. Mass transfer in immobilized cell systems. In: Kuhtreiber W M, Lanza R P, Chick WL (Eds.) Handbook of Cell Encapsulated Technology and Therapeutics. Birh" user and Springer-Verlag (Publ.). 1999, pp. 18-28.

12. McCabe WL, Smith JC. Units of Chemical Engineering, McGraw-Hill, New York, 1985, p. 602.

13. Heath C, Belfort G. Immobilization of suspended mammalian cells: Analysis of hollow fiber and microcapsule bioreactors. Advances in Biochemical Engineering/Biotechnology, 1987, 34: 1-31.

14. Van't Riet K. Review of measuring methods and results in nonviscous gas-liquid Mass Transfer in Stirred Vessels". Ind. Eng. Chem. Process Des. Dev.,1979, 18: 357-364.

15. King G A, Daugulis AJ, Faulkner P, Goosen MFA. Alginate-polylysine microcapsules of controlled membrane molecular weight cut-off for mammalian cell culture engineering, Biotechnology Progress, 1987, 3: 231-240.

16. Bugarski B, Amsden B, Neufeld RJ, Poncelet D, Goosen MFA. Effect of electrode geometry and charge on the production of polymer microbeads by electrostatics". CJChE, 1994, 72:517-521. 


\section{MFA Goosen}

17. De Shon E W, Carlson R. Electric field and model for electrical liquid spraying. J. Colloid Sci,. 1968, 28: 161-166.

18. Weast RC. Handbook of Chemistry and Physics, 59th Ed. CRC Press Inc., Boca Raton, FL, 1979, p. F45.

19. Al-Hajry, H. A., S. A., Al-Maskary, L. M., Al-Kharousi, O., El-Mardi, W. H., Shayya, and M. F. A. Goosen. 1999. Encapsulation and Growth of plant Cell Cultures in Alginate, Biotechnot. Progress. 15(4): 768-774.

20. Bugarski B, Smith J, Wu MFA, Goosen MFA. Methods of animal cell immobilization using electrostatic droplet generation. Biotechnol. Tech, 1993, 6 (9): 677-682.

21. Bugarski B, Li O, Goosen MFA, Poncelet R, Vunjak NV. Electrostatic droplet generation: Mechanism of polymer droplet formation. AIChE. J., 1994, 40 (6): 1026-1031.

22. Goosen MFA, Mahmoud ESE, Al-Ghafri H A, AlHajri YS, Bugarski AB.. Immobilization of cells using electrostatic droplet generation. In: Bickerstaff G, Ed. Methods in molecular biology: Immobilization Enzymes and Cells. Humana Press, Totowa, NJ, 1996, pp. 167-174.

23. Goosen MFA, Al-Ghafri AS, El-Mardi O, Al-Belushi MIJ, Al-Hajri HA, Mahmoud ESE, Consolacion EC. Electrostatic droplet generation for encapsulation of somatic tissue: Assessment of high voltage power supply. Biotechnology Progress, 1997, 13(4):497-502.

24. Klein J, Stock J, Vorlop DK. Pore size and properties of spherical calcium alginate biocatalysts. Eur. J. Appl. Microb. Biotechnol., 1993, 18: 86.
25. Goosen MFA, O'Shea GM, Gharapetian MM, Sun A. Immobilization of living cells in biocompatible semipermeable microcapsules: Biomedical and potential biochemical engineering applications. In: Polymers in Medicine. Chiellini E. Ed. Plenum Publishing, New York, 1986, p 235

26. Teng W, Liu LYJ, Tsai VC, Soong TS. Somatic embryogenesis of carrot in bioreactor culture systems. Hort. Sci, 1994, 29 (11): 1349-1352.

27. Shigeta J. Germination and growth of encapsulated somatic embryos of carrot for mass propagation. Biotechnol. Tech., 1995, 10 (9), 771-776.

28. Piccioni E. Plantlets from encapsulated micropropagated buds of M.26 apple rootstock. Plant Cell, Tissue and Organ Culture, 1997, 47: 255-260.

29. King GA, Daugulis AJ, Faulkner P, Bayly D, Goosen MFA Alginate concentration a key factor in growth of temperature-sensitive insect cells in microcapsules. Biotechnol. Bioeng., 1989, 34:1085-1091.

30. Chang TMS, Prakash S. Therapeutic uses of microencapsulated genetically engineered cells. Molecular Medicine Today. 1988, 4(5): 221-227.

31. Harel $P$, Mignot L, Sauvage JP, Junt GA. Cadmium removal from dilute aqueous solution by gel beads of sugar beet pectin. Industrial Crops and Products, 1988, 7:239-246. 